\title{
A Study on the Psychological Status of the Caregivers to Patients Out of ICU after Craniocerebral Tumor Surgery and Their Factors
}

\author{
Ying Li, Daili Zou, Yu Yang, Yunjia Li, Qinqin Zhao, Zhihuan Zhou* \\ Sun Yat-sen University Cancer Center, Guangzhou, China \\ Email: *liying@sysucc.org.cn
}

How to cite this paper: Li, Y., Zou, D.L., Yang, Y., Li, Y.J., Zhao, Q.Q. and Zhou, Z.H. (2021) A Study on the Psychological Status of the Caregivers to Patients Out of ICU after Craniocerebral Tumor Surgery and Their Factors. Neuroscience \& Medicine, 12, 1-11.

https://doi.org/10.4236/nm.2021.121001

Received: December 29, 2020

Accepted: March 6, 2021

Published: March 9, 2021

Copyright $\odot 2021$ by author(s) and Scientific Research Publishing Inc. This work is licensed under the Creative Commons Attribution International License (CC BY 4.0).

http://creativecommons.org/licenses/by/4.0/

\begin{abstract}
Objective: So as to provide a theoretical basis for the future development of intervention measures to reduce the negative psychological mood of caregivers. To investigate the psychological status of the main caregivers for patients who were transferred out of ICU after craniocerebral tumor surgery and analyze their factors. Methods: 112 patients with cerebral tumor surgery were reviewed from sun yat-sen university cancer hospital. The research object is caregivers. The general data questionnaire, hospital anxiety depression scale and migration of ICU patients' family members stress questionnaire scale investigation are collected. Multiple linear regression analysis in cerebral tumor patients with postoperative ICU transition out main factors influencing the psychological condition of the caregivers. Results: The anxiety and depression scores were $(15.60 \pm 5.83)$ and $(38.73 \pm 3.23)$ respectively. The results of multiple regression analysis showed that the gender, education level, relationship with the patient and family monthly income of the primary caregivers of the patients were the influencing factors of anxiety, depression and migration stress psychological state $(\mathrm{P}<0.05)$. Conclusion: The main caregivers of patients who were transferred out of ICU after craniocerebral tumor surgery had relatively severe anxiety, depression and migration stress. Medical staff should pay attention to the psychological status of caregivers and take effective measures to promote their physical and mental health.
\end{abstract}

\section{Keywords}

Craniocerebral Tumor Surgery, ICU Transition Period, Caregivers,

Psychological Status, Factors Affecting 


\section{Introduction}

Brain cancer and other nervous system accounted for only $1 \%$ of all new cancer cases $-4 \%$, about $3 \%$ of cancer deaths [1], due to such risky surgery for brain tumor resection, traumatic, postoperative condition changes quickly, prone to all kinds of serious postoperative complications, postoperative patients will transition into the ICU observation, stay in stable condition after back to ordinary ward. After patients postoperative ICU admission, because the ICU strict visiting system that patients and families apart, unable to visit or escort, and impact on family psychology, the main caregivers of disease-related knowledge is insufficient, readiness is low, can lead to major caregivers to take care of the difficulties and adverse emotional, psychological anxiety depression and pain [2]. On the one hand, family members worry about the operation effect and whether the patient can safely survive the crisis after the operation., on the other hand, because of not personally take care of the patient and family not to understand the status of the patients with disease, the lack of the understanding of treatment and care, the family members of patients sense of uncertainty about events, affect their mental health, there is a lot of psychological problems [3], and family members is a major social support system of the patients, the rehabilitation plays an important role in [4] domestic study on the status of the ICU family mental patients in ICU can produce a great pressure to the patients families [5] [6] [7] [8], counter rotating out of the patient's family migration stress phenomenon seriously insufficient. Therefore, it is necessary to pay attention to the investigation and study on the psychological status of the primary caregivers of patients who were transferred out of ICU after craniocerebral tumor surgery. The purpose of this study is to understand the psychological status of the main caregivers of patients transferred out of ICU after brain tumor surgery in China, and to identify the influencing factors of the psychological status of the main caregivers of patients transferred out of ICU after brain tumor surgery, so as to provide a theoretical basis for the future development of intervention measures to reduce the negative psychological mood of caregivers.

\section{Objects and Methods}

\subsection{Research Objects}

The main family caregivers of 112 craniocerebral tumor patients hospitalized in the department of Neurosurgery of a third-grade A tumor hospital in Guangzhou from April to July 2020 were selected as the research objects by adopting the convenience sampling method. Inclusion criteria for patients: they were pathologically diagnosed as craniocerebral tumor and admitted to ICU after surgery, $\geq 72 \mathrm{~h}$. The inclusion criteria of the main caregivers are: 1) the spouse, parents, children and other relatives of the patient; Undertake the primary care of patients in their daily life, with continuous care exceeding 72 hours, and designated by the patient as the primary caregiver; Older than 18 years; 2) Normal cognitive function, can complete the questionnaire; Informed consent, voluntary 
participation. Exclusion criteria: caregivers with mental disorders or cognitive communication disorders.

\subsection{Methods}

\subsubsection{Research Tools}

1) General information questionnaire: The researcher designed the questionnaire by himself by referring to the literature, including gender, age, religious belief, educational level, family monthly income, place of residence, relationship with the patient, marital status, degree of knowledge of the patient's condition, payment method of the patient's treatment, length of stay in ICU, etc.

2) The Hospital Anxiety and Depression Scale (HADS) was compiled by Zigmond and Snaith [9] in 1983. It is widely used in the screening of Anxiety and Depression in medical institutions, including two subscales, Anxiety (A) and Depression (D), which are composed of 7 items for Anxiety and Depression respectively, and each item is scored 0 - 3 points. The score interval of HADS-A and HADS-D subscales was as follows: 0 - 7 was classified as asymptomatic; 8 10 is classified as suspected presence of symptoms; Eleven to twenty-one is classified as definitely symptomatic. At the time of scoring, the critical value of screening is $\geq 8$, that is, the suspicious and symptomatic persons are all positive [10]. The Cronbach's coefficients of the master table, haDS-A and HADS-D subscales were $0.879,0.806$ and 0.806 , respectively, and the correlation coefficients (ICC) in the retarged-reliability group were $0.945,0.921$ and 0.932 , respectively. The correlation coefficients of the HADS summary table and the HADS-A and HADS-D subscales ranged from 0.596 to 0.685 .

3) The Family Relocation Stress Scale (FRSS) was developed by Hyun et al. [11] to measure the migration Stress level of Family members of PATIENTS transferred out of ICU. In this paper, a Chinese Scale translated by Wang Yonghua [12] was adopted. The scale consists of 14 items in 4 dimensions: cognition of general ward environment and care (6 items), cognition of critical condition (3 items), cognition of separation anxiety ( 3 items), and cognition of withdrawal ( 2 items). Likert 4 -point scoring method was used for each item ( $1=$ strongly disagree, 2 = disagree, $3=$ agree, $4=$ strongly agree). The total Cronbach's of the scale was 0.857 , and the Cronbach's coefficients of each dimension were $0.858,0.849,0.800$ and 0.849 , respectively. The scale scores ranged from 14 to 56 , and the higher the score was, the more severe the migratory stress was in the families of ICU patients.

\subsubsection{Survey Methods}

On-site investigation was conducted on the subjects meeting the inclusion criteria by the researcher himself. On the day after surgery, a questionnaire was sent to the family members of the selected patients before they were transferred out of the ICU from the operating room. Unified guidance was used to introduce the purpose and significance of the survey to the research subjects, and the research subjects filled in the questionnaire by themselves. For those who could not com- 
plete the questionnaire by themselves, the researcher stated one by one, and the researcher filled in the questionnaire on their behalf after the research subjects chose the answers. The questionnaire will be issued on the spot and recalled on the spot. Check whether the questionnaire is complete. If there is any omission, complete it on the spot. In this study, 120 questionnaires were distributed and 112 were collected, with an effective recovery rate of $93.33 \%$.

\subsubsection{Statistical Methods}

SPSS 21 software was used for statistical analysis of data. Measurement data were expressed as mean \pm standard deviation. Counting data are described by frequency and composition ratio. Independent sample $\mathrm{T}$ test and one-way an OVA were used for the comparison between groups. Pearson correlation analysis was used for the normal distribution data of continuous variables, and multiple linear regression analysis was used for multi-factor analysis. The test level was in $=0.05$ and out $=0.10 . \mathrm{P} \& \mathrm{lt}$; A difference of 0.05 was statistically significant.

\section{The Results}

\subsection{Describe the Current Situation of Psychological Anxiety, Depression and Stress of Main Caregivers in ICU Transition Period after Craniocerebral Surgery (Table 1)}

The anxiety and depression scores $(15.60 \pm 5.83)$ of the main caregivers of patients who were transferred out of ICU after craniocerebral tumor surgery were measured in two dimensions: anxiety $(8.72 \pm 3.35)$ and depression $(6.88 \pm$ 3.01).The score of migration stress was $(38.73 \pm 3.23)$, and the order of the four

Table 1. (a) Anxiety and depression scores of main caregivers of patients transferred out of ICU in transition period after craniocerebral operation $(n=112)$; (b) Stress migration entry scores of main caregivers of patients transferred out of ICU in transition period after craniocerebral operation $(n=112)$.

(a)

\begin{tabular}{cccc}
\hline project & $\begin{array}{c}\text { Number of } \\
\text { entries }\end{array}$ & $\begin{array}{c}\text { Range of } \\
\text { points (points) }\end{array}$ & $\begin{array}{c}\text { Equipartition of } \\
\text { dimensions }(\bar{x} \pm s)\end{array}$ \\
anxiety & 7 & $0-21$ & $8.72 \pm 3.35$ \\
depression & 7 & $0-21$ & $6.88 \pm 3.01$ \\
Overall score for anxiety and depression & 14 & $0-42$ & $15.60 \pm 5.83$ \\
\hline
\end{tabular}

(b)

\begin{tabular}{cccccc}
\hline The dimension & $\begin{array}{c}\text { Number of } \\
\text { entries }\end{array}$ & $\begin{array}{c}\text { The minimum } \\
\text { value }\end{array}$ & $\begin{array}{c}\text { The } \\
\text { maximum }\end{array}$ & $\begin{array}{c}\text { Divide entries } \\
(\bar{x} \pm s)\end{array}$ \\
\hline General ward environment and care & 6 & 13 & 23 & $2.53 \pm 0.67$ \\
Awareness of the patient's critical condition & 3 & 5 & 11 & $2.88 \pm 0.72$ \\
Cognition of separation anxiety & 3 & 3 & 12 & $2.60 \pm 0.75$ \\
Turn out cognition & 2 & 4 & 8 & $2.32 \pm 0.68$ \\
Total migration stress score & 14 & 28 & 47 & $38.73 \pm 3.23$ \\
\hline
\end{tabular}


dimensions from high to low was: the cognitive dimension of critical condition $(2.88 \pm 0.72)$, the cognitive dimension of separation anxiety $(2.60 \pm 0.75)$, the cognitive dimension of general ward environment and nursing $(2.53 \pm 0.67)$, and the cognitive dimension of transfer $(2.32 \pm 0.68)$. See Table 1(a) and Table 1(b).

\subsection{Differences in the Scores of Psychological Anxiety, Depression and Stress Migration of the Main Caregivers of Patients with Transitional Period Leaving ICU after Craniocerebral Operation with Different Characteristics (Table 2)}

Table 2. Differences in psychological anxiety, depression and stress scores of main caregivers of patients transferred out of ICU after craniocerebral operation with different characteristics $(n=112)$.

\begin{tabular}{|c|c|c|c|c|c|}
\hline project & $\begin{array}{l}\text { The number } \\
\text { of cases }\end{array}$ & $\begin{array}{c}\text { Anxiety and } \\
\text { depression score } \\
(\bar{x} \pm s)\end{array}$ & $\begin{array}{l}\text { Migratory stress } \\
\text { score }(\bar{x} \pm s)\end{array}$ & $\begin{array}{l}\text { F/T value (anxiety } \\
\text { depression/ } \\
\text { migration stress) }\end{array}$ & $\begin{array}{l}\text { P value (anxiety, } \\
\text { depression/ } \\
\text { migration stress) }\end{array}$ \\
\hline gender & & & & $1.932 / 1.092$ & $0.05 / 0.042$ \\
\hline male & 62 & $14.79 \pm 5.58$ & $22.83 \pm 2.61$ & & \\
\hline female & 50 & $18.36 \pm 6.17$ & $27.52 \pm 2.57$ & & \\
\hline age & & & & $0.719 / 3.867$ & $0.742 / 0.942$ \\
\hline $19-34$ & 35 & $15.17 \pm 5.42$ & $25.40 \pm 2.51$ & & \\
\hline $35-59$ & 71 & $16.15 \pm 5.97$ & $24.93 \pm 2.67$ & & \\
\hline$\geq 60$ & 6 & $11.50 \pm 5.32$ & $26.17 \pm 2.40$ & & \\
\hline Marital status & & & & $1.864 / 1.051$ & $0.149 / 0.875$ \\
\hline unmarried & 13 & $13.23 \pm 4.65$ & $24.61 \pm 2.32$ & & \\
\hline married & 94 & $15.97 \pm 5.85$ & $25.13 \pm 2.63$ & & \\
\hline Divorced/separated & 4 & $17 \pm 6.68$ & $26.00 \pm 2.82$ & & \\
\hline Death of a spouse & 1 & 6 & 29 & & \\
\hline Level of education & & & & $10245 / 14.899$ & $0.016 / 0.001$ \\
\hline Primary school & 13 & $20.00 \pm 5.55$ & $26.65 \pm 2.01$ & & \\
\hline Junior high school & 22 & $16.82 \pm 5.37$ & $26.47 \pm 1.91$ & & \\
\hline High school or technical secondary school & 30 & $14.20 \pm 6.17$ & $25.16 \pm 2.32$ & & \\
\hline college & 21 & $13.86 \pm 5.24$ & $23.45 \pm 2.50$ & & \\
\hline Bachelor and above & 26 & $12.38 \pm 5.41$ & $22.76 \pm 2.24$ & & \\
\hline professional & & & & $2.550 / 14.644$ & $0.056 / 0.895$ \\
\hline workers & 20 & $15.30 \pm 4.52$ & $23.55 \pm 2.74$ & & \\
\hline farmers & 21 & $18.62 \pm 6.38$ & $23.09 \pm 1.51$ & & \\
\hline clerk & 44 & $14.50 \pm 6.13$ & $26.11 \pm 2.58$ & & \\
\hline soho & 27 & $15.26 \pm 5.20$ & $26.33 \pm 1.51$ & & \\
\hline Relationship with patients & & & & $3.785 / 6.082$ & $0.042 / 0.001$ \\
\hline spouse & 49 & $18.08 \pm 5.90$ & $27.66 \pm 2.16$ & & \\
\hline children & 55 & $15.58 \pm 5.85$ & $25.60 \pm 2.51$ & & \\
\hline
\end{tabular}


Continued

\begin{tabular}{|c|c|c|c|c|c|}
\hline Other relatives & 2 & $13.17 \pm 5.77$ & $24.20 \pm 0.00$ & & \\
\hline parents & 6 & $15.50 \pm 0.70$ & $25.12 \pm 2.16$ & & \\
\hline To live & & & & $3.888 / 0.098$ & $0.023 / 0.907$ \\
\hline city & 38 & $15.13 \pm 5.36$ & $25.13 \pm 3.13$ & & \\
\hline Cities and towns & 28 & $13.54 \pm 5.97$ & $25.32 \pm 2.19$ & & \\
\hline rural & 46 & $17.24 \pm 5.75$ & $25.04 \pm 2.51$ & & \\
\hline $\begin{array}{l}\text { The extent to which farmers knew the dise } \\
\text { of patients }\end{array}$ & & & & $0.896 / 0.695$ & 0.9870 .907 \\
\hline All know & 61 & $14.93 \pm 6.08$ & $24.92 \pm 2.56$ & & \\
\hline Part of the unknown & 50 & $16.42 \pm 5.51$ & $25.24 \pm 3.01$ & & \\
\hline don't know & 1 & 15 & 24 & & \\
\hline Monthly household income (yuan) & & & & $1.199 / 14.910$ & $0.041 / 0.000$ \\
\hline$<3000$ & 25 & $17.08 \pm 7.18$ & $27.57 \pm 1.95$ & & \\
\hline $3000-5000$ & 38 & $16.32 \pm 5.48$ & $26.38 \pm 2.41$ & & \\
\hline $5000-7000$ & 19 & $14.42 \pm 5.32$ & $26.11 \pm 1.76$ & & \\
\hline $7000-9000$ & 16 & $13.94 \pm 2.97$ & $24.82 \pm 2.41$ & & \\
\hline$>9000$ & 14 & $12.50 \pm 6.89$ & $22.76 \pm 1.78$ & & \\
\hline How patients are paid for treatment & & & & $1.897 / 6.73$ & $0.873 / 0.546$ \\
\hline At his own expense & 3 & $15.53 \pm 2.34$ & $23.35 \pm 1.76$ & & \\
\hline Residents of social security & 78 & $15.65 \pm 3.47$ & $25.34 \pm 1.89$ & & \\
\hline Commercial insurance & 31 & $14.75 \pm 3.25$ & $26.43 \pm 3.67$ & & \\
\hline Days in ICU & & & & $5.674 / 4.788$ & $0.897 / 0.032$ \\
\hline $2-4$ & 82 & $16.25 \pm 2.45$ & $24.67 \pm 3.65$ & & \\
\hline $4-7$ & 25 & $17.23 \pm 2.31$ & $25.23 \pm 4.32$ & & \\
\hline$>7$ & 5 & $16.25 \pm 3.45$ & $27.24 \pm 3.54$ & & \\
\hline
\end{tabular}

3.3. Multiple Linear Regression Analysis of Psychological Anxiety, Depression and Stress Migration Influencing Factors of Main Caregivers of Patients Transferred Out of ICU after Craniocranial Surgery (Table 4(a) and Table 4(b))

The total scores of psychological anxiety, depression and stress migration of the main caregivers of patients transferred out of ICU after craniocervical surgery were taken as dependent variables, and the variables with statistical significance in univariate analysis were taken as independent variables for multiple linear regression analysis. The values of independent variables were shown in Table 3. According to the results of regression analysis, gender, degree of education, relationship with patients, and monthly family income were the influencing factors of psychological anxiety, depression and stress migration of the main caregivers of patients who were transferred out of ICU after craniocranial surgery (P \& LT; 0.05). See Table 4(a) and Table 4(b) for details. 
Table 3. Assignment table of independent variables.

\begin{tabular}{|c|c|}
\hline The independent variables & The assignment \\
\hline gender & male $=1$ female $=0$ \\
\hline \multicolumn{2}{|l|}{$\begin{array}{l}\text { Relationship with patient (with spouse } \\
\text { as reference) }\end{array}$} \\
\hline Relationship with the patient 1 & children $=1 \quad$ Other relatives $=0 \quad$ parents $=0$ \\
\hline Relationship with the patient 2 & spouse $=0 \quad$ children $=0 \quad$ Other relatives $=1 \quad$ parents $=0$ \\
\hline Relationship with the patient 3 & spouse $=0 \quad$ children $=0 \quad$ Other relatives $=0 \quad$ parents $=1$ \\
\hline Joul of educotion & Primary schools and below $=1 \quad$ Junior high school $=2$ \\
\hline Lever or eacucation & college $=4 \quad$ Bachelor and above $=5$ \\
\hline Monthly household income(yuan) & $\begin{aligned}<3000= & 1 \quad 3000-5000=2 \quad 5000-7000=3 \\
& 7000-9000=4 \quad>9000=5\end{aligned}$ \\
\hline
\end{tabular}

Table 4. (a) Multivariate linear regression analysis of the influential factors of anxiety and depression in the main caregivers of patients with transitional period of ICU transition after craniocranial tumor surgery $(\mathrm{n}=112)$; (b) Multivariate linear regression analysis of the main factors influencing migration stress of caregivers for patients with transitional period of ICU transition after craniocranial tumor surgery $(n=112)$.

(a)

\begin{tabular}{cccccc}
\hline variable & $\boldsymbol{B}$ value & $\boldsymbol{S} E$ values & $\boldsymbol{\beta}$ value & $\boldsymbol{t}$ value & $\boldsymbol{P}$ value \\
\hline constant & 20.303 & 3.652 & & 5.845 & 0.000 \\
gender & 1.654 & 2.330 & 0.056 & 2.281 & 0.001 \\
Level of education & -3.353 & 1.262 & -0.759 & -2.659 & 0.009 \\
\hline & Relationship with patient (with spouse as reference) & -0.184 & 0.005 \\
children & -0.355 & 1.934 & -0.031 & -1.799 & 0.007 \\
Other relatives & -8.470 & 4.709 & -0.193 & -0.910 & 0.005 \\
parents & -3.137 & 3.449 & -0.122 & -1.375 & 0.002 \\
\hline
\end{tabular}

(b)

\begin{tabular}{cccccc}
\hline variable & B value & SE values & $\beta$ value & $t$ value & $P$ value \\
constant & 40.396 & 1.277 & & 31.786 & 0.000 \\
gender & 1.787 & 1.118 & 0.303 & 1.598 & 0.010 \\
Level of education & -2.042 & 0.858 & -0.827 & -2.380 & 0.005 \\
\hline & Relationship with patient (with spouse as reference) & \\
children & -1.771 & 1.060 & -0.272 & -1.671 & 0.005 \\
Other relatives & -2.311 & 2.286 & -0.133 & -1.011 & 0.006 \\
parents & -3.562 & 2.223 & -0.282 & -1.586 & 0.011 \\
Monthly household income & -2.459 & 0.810 & -1.001 & -3.034 & 0003 \\
\hline
\end{tabular}

Note: $\mathrm{R}^{2}=0.142$, adjustment $\mathrm{R}^{2}=0.093, \mathrm{~F}=2.887, \mathrm{P}<0.001$. 


\section{Discussion}

\subsection{The Main Caregivers of Patients Transferred Out Of ICU after Craniocervical Surgery Have Psychological Conditions of Anxiety, Depression and Stress Migration}

The results showed that patients with cerebral tumor postoperative ICU transition out main caregivers migration stress score $(38.73 \pm 3.23)$, in the average level, this has to do with Wang YH [13] stress status of ICU patients' family migration score (34.49 \pm 6.03$)$, anxiety, depression score (15.60 \pm 5.83$)$, and this Kong Zhenxiao similar [14], tip: patients with craniocerebral surgery ICU transition out primary caregivers of psychological state of anxiety, depression and stress migration. The highest mean score of items was "critical patient cognitive dimension" (2.88 \pm 0.72$)$, and the lowest was "roll-out cognitive dimension score" $(2.32 \pm 0.68)$. In a critical condition in patients with cognitive dimensions of the cause of the highest score is likely to be admitted to the care of the patient are critical and changeful, requires close monitoring of vital signs, although the ICU patients has been out of danger, can turn out of the ICU, but his family has not yet recovered from the patients with tumor surgery, that patient is still in a vulnerable period, to the patient is still in a state of fear. Chaboyer scholars [15] that ambivalence is peculiar to the ICU patients' family members in complex emotions, on the one hand, family members will be reduced because of the common ward nurses and monitoring equipment and feel anxious and nervous, fear to attended house can cause bad effects to the recovery of the patients, families, on the other hand think from explain the patient care unit turn out better, time is limited, and care unit allows families visit patients in general wards of visiting the care unit loose, families for pleasure to the patient's side.

\subsection{Analysis of Influencing Factors of Psychological Status of Main Caregivers of Patients Transferred Out of ICU after Craniocerebral Tumor Surgery}

The scores of anxiety, depression and stress migration of female caregivers were higher than that of male caregivers

The scores of anxiety, depression and stress migration of female caregivers were higher than that of male caregivers, of our study results were consistent with Mali [16], could women born delicate feeling, sensitive, suspicious, compressive ability, emotion regulation ability is weak, facing a loved one is thought to cure brain tumor hope is not big, can't stop crying, is easy to cause psychological anxiety, depression and other adverse reaction [17], is easier to keep pessimistic attitude and adopt the negative coping styles. Compared with women, male caregivers are more calm and calm in the face of difficulties and setbacks, have higher stress tolerance and ability to deal with problems rationally, and have a more positive and optimistic attitude towards future planning. Therefore, medical staff should pay more attention to female caregivers and provide them with timely emotional support to relieve anxiety, depression, painful stress mi- 
gration and other negative emotions.

The lower the educational level of caregivers, the higher the scores of anxiety, depression and stress migration of caregivers

The lower the educational level of caregivers, the higher the scores of anxiety, depression and stress migration of caregivers, which is consistent with the research results of Brodsky et al. [18]. The possible reasons are as follows: caregivers with higher education have higher cognitive level, can view problems from a more comprehensive perspective, have a deeper understanding of life and the operation, mode and follow-up of craniocerebral tumor, and have a more indifferent attitude towards life. But they will also actively obtain more information and resources about the treatment of diseases through various ways, and be positive about the treatment. On the contrary, carers with junior high school education or below are deficient in disease cognition, treatment understanding and self-regulation ability when the disease changes. In addition, most caregivers with low education level have low socioeconomic status and weak social support, and lack of ability to cope with negative events and make use of social support [18]. The high medical expenses and care burden make caregivers feel helpless, which increases the scores of anxiety, depression and stress migration of caregivers.

The scores of anxiety, depression and stress migration of spouses were significantly higher than those of other caregivers

This study showed that the scores of anxiety, depression and stress migration of spouses were significantly higher than that of other caregivers including children, which was similar to the results of Bernard et al. [19], who found that spouses had weaker psychological adjustment and coping ability to major stress events than their children. The reason may be that the spouse is the patient's closest lover, who lives with the patient day and night for a long time, depending on each other and supporting each other. Spouses have more difficulty than other caregivers in dealing with sad emotional responses. Therefore, when facing the spouse of the patient, the medical staff should be more patient and kind, and try to use plain language to introduce the patient's condition, treatment and prognosis. At the same time, listen to the family, understand their psychological needs, give positive psychological support and encouragement.

The lower the family monthly income, the higher the scores of anxiety, depression and stress migration of caregivers

The lower the monthly income of the family, the higher the scores of anxiety, depression and stress migration of the caregivers. The high medical expenses and care burden make the caregivers feel helpless, which aggravates the scores of anxiety, depression and stress migration of the caregivers. The research of Park scholar [20] also found that the occurrence of migration stress in the family members of ICU patients was related to their economic strength. The worse the economic status was, the higher the score of migration stress was and the greater the risk was. High risk of craniocerebral surgery, poor prognosis, high cost of operation plus radiotherapy and chemotherapy, and high cost of treatment and 
care in ICU cause huge psychological burden on the families of ICU patients.

\section{Summary}

To sum up, the main caregivers in the transitional period of ICU after craniocerebral operation are more serious in psychological anxiety, depression and migration stress. Psychological anxiety, depression and migration stress are common among the primary caregivers of patients who are transferred out of ICU after craniocerebral operation. Many scholars [21] [22] believe that the lack of necessary information exchange and communication between medical staff and their families is an important cause of migration stress. Therefore, according to the characteristics of family caregivers' psychological state, clinical medical workers should pay attention to key groups, understand caregivers, and communicate with caregivers through various channels to promote their physical and mental health. Application of psychological intervention to ease taking care of negative emotions and migration of mental stress.

This research still has certain limitation, only a convenience sampling survey of the Guangzhou three cancer hospital neurosurgery transfer 112 ICU patients' families, sample representativeness, suggest a larger sample of multicenter study in the future, to make up for any deficiencies in this study, further explore the occurrence of stress transfer ICU patients' families migration characteristics and preventive intervention strategy, prompting transition of ICU patients and family members to ordinary ward.

\section{Conflicts of Interest}

The authors declare no conflicts of interest regarding the publication of this paper.

\section{References}

[1] Ostrom, Q.T., Bauchet, L., Davis, F.G., et al. (2014) The Epidemiology of Glioma in Adults: A "State of the Science" Review. Neuro-Oncology, 16, 896-913. https://doi.org/10.1093/neuonc/nou087

[2] Li, T., Gong, Y.-L., Sha, F., Dong, X., Miao, C.X. and Liu, Y.L. (2012) Analysis on the Status Quo and Influencing Factors of Primary Caregiver Readiness of Transferred ICU Patients. Nursing Management in China, 18, 1347-1351.

[3] Liu, H.J., Wu, M.L., Fang, H.P. and Liao, Z.F. (2015) Correlation between Family Members' Sense of Disease Uncertainty and Quality of Life of ICU Patients in Neurosurgery. Journal of Nursing, 30, 10-13.

[4] Ding, L., Ding, M. and Zhu, J.H. (2013) Research Progress of Family Needs Assessment and Support System for ICU Patients. Chinese Journal of Nursing, 48, 953-955.

[5] Chen, C. (2008) Application of the Family Demand Scale for Critically Ill Patients in Improving ICU Nursing Satisfaction. Psychologist, 24, 255-256.

[6] Yang, J. and Bai, Y.J. (2017) Research Status and Intervention Measures of Post-ICU Syndrome in Family Members. Nursing Research, 31, 2582-2584.

[7] Sun, S.X., Gan, X.N. and Zhang, X.D. (2017) Establishment and Reliability and Validity Test of Stress Assessment Scale for Family Members of Patients Transferred 
from ICU. Chinese Journal of Practical Nursing, 33, 490-495.

[8] Han, J., Chen, D.L., Wang, M.N., et al. (2008) Attachment Psychology and Migration Stress of Family Members of Transferred ICU Patients: An Analysis of the Mediating Effect of Empirical Avoidance. Chinese Journal of Modern Nursing, 24, 3891-3896.

[9] Zigmond, A.S. and Snaith, R.P. (1983) The Hospital Anxiety and Depression Scale. Acta Psychiatrica Scandinavica, 67, 361-370. https://doi.org/10.1111/j.1600-0447.1983.tb09716.x

[10] Zhang, P. and Wang, Y. (2019) Effect of Middle and High Posture Baduan Jin on Anxiety, Depression and Quality of Life in Patients with Ulcerative Colitis. Chinese Journal of Modern Nursing, 25, 81-85.

[11] Oh, H.S., Lee, S., Kim, J.S., Lee, E.J., Min, H.N., Cho, O.J. and Seo, W.S. (2015) Clinical Validity of a Relocation Stress Scale for the Families of Patients Transferred from Intensive Care Units. Journal of Clinical Nursing, 24, 1805-1814.

[12] Wang, Y.-H., Shao, S.-W., Zhuang, Y.-Y. and Jin, G. (2012) Sinicization and Reliability and Validity Evaluation of Migration Stress Scale for ICU Patients. Journal of Nursing Education, 33, 776-779.

[13] Wang, Y.-H., Shao, S.-W., Zhuang, Y.-Y. and Jin, G. (2008) Investigation on Migration Stress of Family Members of ICU Patients. Journal of Nursing Education, 33, 2173-2176+2207.

[14] Sun, Z.X., Liu, C.M., Jiao, L.Y., Zhou, T., Yang, L.N. and Fan, J.Y. (2017) A Study on the Reliability and Validity of Hospital Anxiety and Depression Scale. Chinese Journal of Clinicians (Electronic Edition), 11, 198-201.

[15] Chaboyer, W., Kendall, E., Kendall, M., et al. (2005) Transfer Out of Intensive Care: A Qualitative Exploration of Patient and Family Perceptions. Australian Critical Care, 18, 138-141, 143-145. https://doi.org/10.1016/S1036-7314(05)80026-8

[16] Mali, B.I. and Freda, D.G. (2011) Risk Factors Associated with Transfer Anxiety among Patients, Transferring from the Intensive Care Unit to the Ward. Journal of Advanced Nursing, 67, 510-518. https://doi.org/10.1111/j.1365-2648.2010.05497.x

[17] Meadam, J.L., Dracup, K.A., White, D.B., et al. (2010) Symptom Experiences of Family Members of Intensive Care Unit Patients at High Risk for Dying. Critical Care Medicine, 38, 1078-1085. https://doi.org/10.1097/CCM.0b013e3181cf6d94

[18] Brodsky, M. and Dekeyser, G.F. (2011) Risk Factors Associated with Transfer Anxiety among Patients Transferring from the Intensive Care Unit to the Ward. Journal of Advanced Nursing, 67, 510-518. https://doi.org/10.1111/j.1365-2648.2010.05497.x

[19] Bernard, L.L. and Guarnaccia, C.A. (2003) Two Models of Caregiver Strain and Bereavement Adjustment: A Comparison of Husband and Daughter Caregivers of Breast Cancer Hospice Patients. Gerontologist, 43, 808.

https://doi.org/10.1093/geront/43.6.808

[20] Park, J.H., Yoo, M.S., Son, Y.J., et al. (2010) Factors Influencing Relocation Stress Syndrome in Patients Following Transfer from Intensive Care Units. Journal of Korean Academy of Nursing, 40, 307-316. https://doi.org/10.4040/jkan.2010.40.3.307

[21] Cullinane, J.P. and Plowright, C.I. (2013) Patients' and Relatives' Experiences of Transfer from Intensive Care Unit to Wards. Nursing in Critical Care, 18, 289-296. https://doi.org/10.1111/nicc.12047

[22] Li, L. and Zhao, J.J. (2011) A Qualitative Study on the Main Sources of Psychological Stress in Family Members of Surgical ICU Patients. Chinese Journal of Nursing, 28, 15-17. 